Discourse and Communication for Sustainable Education, vol. 9, no. 1, pp. 64-78, 2018

\title{
Second Language Teaching Effectiveness from the Perspective of University Students: A Case Study of Departments of Applied Linguistics
}

\author{
Frough Mehrparvar \\ Marvdasht Branch, Islamic Azad University, Iran \\ Amin Karimnia \\ Fasa Branch, Islamic Azad University, Iran
}

\begin{abstract}
Effective teaching is considered to be one of the factors that can facilitate learner achievement. The present study investigated the indicators that constituted good teaching from the perspective of higher-education students at Applied Linguistics departments, Iran. To do this, following a substantial review of the literature, the five major indicators (with their sub-components) defining teaching effectiveness were identified (viz. Preparation-Organization, Knowledge, Learning-Thinking, Enthusiasm and Delivery). Next, the questionnaire developed by Delaney et al. was administered to 80 higher-education students who were selected through convenience sampling by emails. The open-ended nature of the data needed a manual approach to the analysis and coding of the data. Overall, 13 final characteristics were observed based on the analysis and were further discussed and elaborated on.
\end{abstract}

Keywords: higher education, language education for sustainable development, second language teaching, student evaluation, student-centered teaching.

\section{Introduction}

The main charateristics of sustainable teaching involves incorporationg key sustainable development issues into teaching. This includes, for example, teaching about poverty, disaster risk reduction, climate change reduction and sustainable consumption. Participatory teaching methods are required that empower and motivate learners to change their behaviours and take action for sustainable development. Sustainable teaching consequently promotes competencies like critical thinking and making decisions in a collaborative way.

Effective teaching represents one of the factors that can facilitate learner achievement. Academic centers today seek to reach excellence in learning and teaching, by further exploring the idea of effective teaching (MacGregor, 2003). Effectiveness in teaching is a dynamic ability (Hollins, 2011) and mere reliance on extensive teaching 
experience would not necessarily guarantee effective teaching, because experience can only serve the purpose when an instructor continually adapts classroom techniques to the needs of learners and engages learners in self-reflection. Instructors must be prepared to teach learners who vary in terms of interest, motivation and ability (Adams \& Pierce, 1999). To achieve these goals, researchers interested in teaching effectiveness have explored numerous topics such as teachers' personal characteristics (Thompson \& Thompson, 2008), learners' educational achievement (Yair, 2008), factors influencing learners (Wang et al., 2011), and teachers' beliefs (Shavelson \& Stern, 1981).

Despite the range of these studies, there are lingering questions about how students perceive and evaluate the notion of teaching effectiveness. Students' evaluations of what matters in supporting effective teaching have been resorted to since the 1920s to single out what constitutes bad and good teaching. It is typically accepted that supporting effective teaching (SET) is a "valid, reliable, and worthwhile means of evaluating teaching" (Wachtel, 1998, p. 192). However, after almost a century of research into the effectiveness of such evaluations, there is still controversy about supporting effective teaching validity. The debate points to the fact that educators are skeptical of students' ability to provide objective evaluations of the factors that influence teaching effectiveness (Balam \& Shannon, 2010). Student evaluations are not usually regarded as criteria for teaching effectiveness (Gursoy \& Umbreit, 2005), because of the alleged problem of lack of objectivity in students' perceptions (Strong et al., 2011; Karimnia \& Mohammadjafari, 2017).

As a result, common and facile methods for gathering learner feedback are forms that often contain prescribed characteristics of teaching. However, evaluating teachers based on student feedback-forms alone is problematic. On the one hand, these tools are configured on the assumption that the student respondent and survey designer agree on the features of effective teaching (Delaney et al., 2009). On another hand, the tools may not measure aspects of teaching from students' viewpoints and are designed from the perspective of educators (Wang et al., 2011).

The necessity for a successful construction of a social environment and its protection should be perceived clearly and accepted globally. To this aim, one more need emerges; namely, this is the need for language education which would view a language user as a partner in discussions and negotiations over environmental issues and an interlocutor sensitive to environmental dangers. That is why language education, especially foreign language education becomes an important part of education for sustainable development viewed in a holistic way (Skye, 2015).

Few studies, therefore, have objectively investigated the issue of language teaching effectiveness from the perspective of students. Given the lack of consensus over the usefulness of learner evaluations as a measure of teaching effectiveness, this study seeks to determine what shapes good second language teaching from the perspective of highereducation students at Applied Linguistics departments. The context under investigation is Iranian higher education universities, where students' perceptions of teaching effectiveness have not been assessed fully. Suggesting important implications for the design of student evaluation forms and teacher development programs, this study tries to address two central questions: what are Iranian English Language Teaching (ELT) learners' perceptions of the characteristics of effective teaching in higher education? How do teachers represent these features in higher education from the perspective of Iranian ELT students? 


\section{Background on Effective Teaching}

\section{An Overview of Effective Teaching}

The specifications contributing to the effectiveness of teachers have been explored by many scholars concerned with education. Numerous studies have probed into teaching effectiveness, sustainability and the characteristics of effective teachers, especially as perceived by learners in various contexts worldwide (Barnes \& Lock, 2010; Behroozi \& Karimnia, 2017; Brophy \& Good, 1986; Brosh, 1996; Çoklar \& Yurdakul, 2017; Chen, 2012; Dunkin \& Biddle, 1974; Kalantari \& Karimnia, 2012; Karimnia \& Kay, 2015; Kyriakides et al., 2002; Lee, 2010; Lowman, 1997; Miedema, 2017; Neil, 1991; Pipere, 2016; Salīte, 2015; Iliško, 2007; Thomson, 2008; Wichadee \& Orawiwatnakul, 2012).

Feldman (1978) investigated seventy-two college reports about the characteristics of ideal teachers who could implement effective teaching. The major characteristics prioritized by teachers were arousing interest in learners, clarity and understandability, subject matter knowledgeably, preparedness and course organization, and enthusiasm about teaching and the subject matter. Students, too, preferred some other features such as friendliness, helpfulness, and openness to others' opinions.

Investigating New York City secondary-school principals' views about effective teaching of academic topics, Calabria (1960) found qualities such as motivation, subjectmatter mastery, co-operation, dedication, creativity, control, discipline, standards, efficiency, promptness, sense of humor, with reports/methods, and generosity with time devoted to students. According to some observations, effectiveness in teaching was directly associated with subject matter mastery in the field in question (Chen, 2012).

In another study, Feldman (1988) reviewed thirty one other studies in which faculty members and students had specified the instructional characteristics they attributed to effective instruction and good teaching. Contrary to the faculty members, the students mainly emphasized the quality of activities in the class, being helpful and available and having good elocutionary skills. The faculty members, however, placed more importance on teachers' capability to intellectually challenge learners, motivate students, set high standards for them, and encourage self-initiated learning. Obviously, teachers and students tend to assign different features to teaching effectiveness (Park \& Lee, 2006; Suwandee, 1994).

Axelrod (2008) observed that students' perceptions of what makes up effective instruction transcend mode and time of delivery. He found some degree of consistency between the views of contemporary students about effective teaching and those he gathered from historical memoirs and biographies. As such, Axelrod enumerated seven qualities as "common elements of good teaching," and "transcend time, place, discipline, and instructional type" (p. 24): approachability and accessibility, open-mindedness, fairness, delivery and mastery, enthusiasm, humor, inspiration and knowledge imparted. From a general perspective, the majority of these characteristics could fall under six categories: quality of instruction, pedagogical content knowledge, classroom climate, teachers' beliefs, classroom management, and professional conduct. In the next sub-section, teaching and effectiveness are explored exclusively in language-specific studies. 


\section{Characteristics of an Effective Language Teacher}

The qualities of L2 teachers, too, have been a frequently addressed topic of investigation. Borg (2006) analyzed the ideas of over 200 prospective and practicing English language teachers, along with the opinions of teachers in other fields (e.g. of history, mathematics, chemistry and science), to find the distinctive qualities of language teachers, as opposed to those of other fields. The findings revealed that: (a) the content in English language teaching was more complex and varied than that of other subjects; (b) methods used by language instructors were announced to be different from those in the other fields, while these teachers had to be more progressive and up-to-date; and (c) English language teachers were supposed to have more relaxed, closer, and generally more positive relationships with students in comparison to other instructors.

Effective language teachers are usually expected to have both a set of specific personal qualities and profound competence in the L2 (e.g., tolerance, sensitivity and warmth) (Vadillio, 1999). In an investigation of the characteristics of effective language teachers, Brosh (1996) found these qualities: having knowledge and command of the L2, being able to explain, organize and clarify issues while motivating learners, being fair to learners by avoiding prejudice or favoritism, and being available to learners.

Park and Lee (2006), too, examined the characteristics of effective English teachers as perceived by students and teachers in high schools in Korea, through a self-reporting questionnaire consisting of three categories: pedagogical knowledge, English proficiency and socio-affective skills. Their findings indicated a difference in teachers' perception and students' perception of an effective teacher; more specifically, the teachers chose English proficiency as the most important element, whereas the learners prioritized pedagogical knowledge (for similar studies see Brosh, 1996; Lee, 2010).

These observations are further supported by Wichadee and Orawiwatnakul's study (2012), which demonstrated that both high and low proficiency students placed great emphasis on communication and organizational skills and on teachers' good proficiency of English. A teacher's use of more interesting activities, as well as gentle and supportive personality was also announced to be crucial in creating a good learning atmosphere. Chen (2012) grouped teachers' characteristics into two broad categories: classroom teaching and personal traits. The latter mainly included emotional dimensions such as kindness, fairness, lenience and responsibility, while the former was concerned with skills and techniques of lesson delivery, error correction, language used during teaching, classroom activity organization and classroom atmosphere creation.

Barnes and Lock (2010) emphasized language teachers' supportive and friendly personality, arguing that this quality could significantly reduce students' anxiety and fear, while promoting learning by encouraging them to conveniently use the L 2 in the classroom. Bell (2005) and Lee (2010) highlighted the role of student involvement through group work and learners' exposure to more communicative activities.

Teachers' beliefs represent another highly influential factor that can have an impact on teaching effectiveness. Williams and Burden (1997, pp. 48-9) underscore that teachers' beliefs can, to a great extent, decide what the teaching-learning process is, and in turn influence their practice in the classroom. A substantial body of research recommends that teachers' beliefs about teaching and learning affect their teaching effectiveness (Fang, 1996). Some studies (e.g., Kagathala, 2002; Mansour, 2009) suggested that the relationship between teacher beliefs and effective teaching was a complex one. 
For instance, research has revealed that pre-established beliefs about learning and teaching confines a teacher's ability to be open to new ideas (Horwitz, 1988). Johnson (1992) asserts that instructors enter the field of education with preconceived notions about learning and teaching that guide their classroom practices. Johnston and Janus (2003) further claim that teachers who go through a training program that focuses on audio-lingual and grammar methodologies tend to employ the banking approach to L2 education in their instruction The banking approach to education is a method of learning and teaching where the learners simply store the information passed to them by the teacher. As a result, teaching methodology can be considerably affected by teachers' beliefs (Borg, 2006).

Kissau et al. (2012) examined instructors' preconceived beliefs about teaching, observing that these beliefs varied among teachers. A total of 222 teachers and their supervisors, from different demographic groups, participated in the study. The teachers with 10 or more years of teaching experience were more likely to have strong beliefs in the significance of teaching grammar and were inclined to rely on audio-lingual and grammar-based (GBAL) methods. Their less experienced counterparts, however, while acknowledging the significance of grammar, assumed that extensive focus on grammar rules could hinder the development of oral proficiency.

Given the concerns addressed in this sub-section about the qualities and characteristics of effective language teachers, this study seeks to further contribute to the literature by exploring a context rarely subjected to investigation in terms of teaching effectiveness.

\section{Method}

\section{Research Design}

Defining and highlighting the characteristics of effective teaching in higher education have been the goals of researchers for almost a century. The most widely used questionnaire format to determine students' attitudes about effective academic teaching normally organizes its survey according to the Likert scale followed by a number of open-ended items. To give learners an opportunity to clearly voice their perceptions of effective teaching in higher education, a qualitative method was adopted in this study. In this approach, instead of restricting the range of choices, the participants had the opportunity to liberally express their perception of teaching effectiveness.

\section{Participants}

A total number of 142 higher-education students were selected through convenience sampling by emails and invited to participate in this study. Out of this preselected number of students, 112 students accepted to participate, from whom 80 were selected for the study.

To control the effect of gender, both male and female students were included (35 males and 45 females), and the participants were selected from different Azad university branches. All the participants were M.A. students of Applied Linguistics. Potential participants were informed of the purpose of the study and allowed to opt out of participation. The students who chose to fill out the survey participated voluntarily. The participants were assured of confidentiality and anonymity. 


\section{Instruments}

The instrument used to collect data was adopted from a method developed by Delaney et al. (2009). In their study, they asked participants to identify the characteristics of effective teaching, describe each characteristic, and rank each characteristic in relation to the other characteristics they identified based on a 5 -point Likert scale $(5=$ the most important and $1=$ the least important). In the case of studying university students, the instrument suggests an item that collects data about teachers' behaviors. This particular question was included in the questionnaires distributed in this study.

Although Likert scale questionnaires have been mostly used in studies concerned with students' perception, a new qualitative type of instrument was employed to give students at Islamic Azad University an explicit view on issues on effective teaching. Following Delaney et al. (2010), a 31-item instrument was employed.

\section{Data Collection Procedure}

An electronic method of data collection was employed in this study. The electronic approach is effective for three reasons, according to Delaney et al. (2010, p. 19): (a) its user-friendly format facilitates the process of completing the whole questionnaire; (b) it could cover a large number of students from a variety of university branches without the physical difficulties attached to traditional data collection; and (c) the method helped retrieve the information in a systematic format that could be simply converted into other digital formats and easily processed.

\section{Data Analysis Procedure}

Due to the open-ended nature of the survey items, it was not possible to process the information through computerized statistical packages (e.g. SPSS) that only provided prefabricated options. In fact, the data could involve potential typing errors and other anomalies that had to be recognized by a human user. Therefore, the data were coded manually. Then, the opinions, lists of instructor behaviors, and sets of student comments for each of the characteristics were prepared. Although the manual analysis of the data was time-consuming, it made it possible to have a direct and undisturbed image of the responses' views.

\section{Results}

\section{Inter-coder Consistency Estimates}

To confirm inter-code consistency, the researchers asked two university professors to verify the indicators identified. As a result, $90 \%$ inter-coder agreement was achieved, which was a value that confirmed the reliability of the key characteristics identified and the classifications derived. 


\section{Statistical Report of Characteristics of Effective Teaching}

To determine what characteristics were most prominent in effective teaching as perceived by the higher education students, the significant factors were identified based on the frequency of the choices (Table 1). This section presents and discusses the most frequently mentioned characteristics within each category. In fact, through the following questions, the students tried to argue which teacher characteristics best represented each of the five categories.

a) Preparation and organization: How do you decide whether an instructor is organized and prepared?

b) Knowledge: How do you assess whether a teacher is knowledgeable?

c) Enthusiasm: How does a teacher teach with enthusiasm?

d) Learning and thinking: How does a teacher contribute to your thinking and learning?

e) Delivery: How does a teacher deliver lessons competently?

Having classified and extracted the major themes expressed in the students' openended responses, the researchers reported the frequencies and percentages of the main themes in Table 1.

Table 1

Percentages of the Key Characteristics

\begin{tabular}{ll}
\hline \multicolumn{1}{c}{ Categories and their Perceived Characteristics } & Percent \\
\hline Preparation and organization & \\
\hline Warm and smooth warm-up & $12 \%$ \\
\hline Being responsive to learners' questions and needs & $32 \%$ \\
\hline Fluent and confident in presenting new lesson & $56 \%$ \\
\hline Knowledge & \\
\hline Ability to answer unexpected questions & $38 \%$ \\
\hline Clarity of presentation & $62 \%$ \\
\hline Enthusiasm & $60 \%$ \\
\hline Establishing rapport with learners & $25 \%$ \\
\hline Encouraging learners & $15 \%$ \\
\hline Being energetic & $37 \%$ \\
\hline Learning and thinking & $33 \%$ \\
\hline Question types & $30 \%$ \\
\hline Using teaching techniques \\
\hline Recognizing individual characteristics \\
\hline Delivery & $58 \%$ \\
\hline Performance techniques & $42 \%$ \\
\hline Using teaching aids
\end{tabular}

\section{Preparation and Organization}

The respondents' answer to the question, "How do you decide whether an instructor is prepared and organized?" revealed that the most prominent indicators were warmup, knowing about individual characteristics, and confident presentation of new lessons. 
Fifty-six percent $(56 \%)$ of the respondents perceived how prepared and organized teachers were by evaluating how fluently and confidently the lessons were presented. The ability to explain the concept clearly without reading from slides, explaining materials thoroughly without hesitation, and coming up with answers on the spot were the major indicators of fluent and confident teaching. As Gursoy and Umbreit (2005) explain, teachers who are prepared and organized must first outline clear lesson objectives/goals and must know the topics very well.

Warm-up activities were mentioned by 12 percent $(12 \%)$ of the respondents as another indicator of Preparation/Organization, suggesting that teachers must try to have an initial positive impression on the learners to enhance their motivation and sense of belonging. Thirty-two percent $(32 \%)$ of the participants also viewed responsiveness to learners' questions and needs as evidence of organization and preparation.

\section{Knowledge}

The respondents were asked about how they evaluated the knowledgeability of an instructor. Their responses highlighted the value of teachers' pedagogical content knowledge (Shulman, 1986). Here, the main indicators of teaching effectiveness were teachers' ability to answer unexpected questions and clear, learner-friendly presentation. The respondents $(38 \%)$ believed that teachers' ability to answer questions posed by students would help them assess how knowledgeable their teachers were. In their comments, the respondents stated that teachers' Knowledge was a reliable source of information that could help students invest trust in their teachers. This revealed that the students evaluated teachers as content specialists.

Knowledgeable teachers were also evaluated based on the way they communicated or answered questions; these qualities had two aspects: on the one hand, the students were concerned about teachers' confidence, willingness and promptness, and on the other, they focused on the quality of the answers in terms of sufficiency, clarity and concision. Sixty-two percent $(62 \%)$ of the students highlighted the importance of the quality and clarity of teachers' presentation of new lessons as evidence for teachers' Knowledge.

\section{Enthusiasm}

The respondents' answers to the question, "How does an instructor teach with enthusiasm?", clarified that $60 \%$ of the respondents emphasized instructors' warm and friendly relationship with their students (establishing interpersonal rapport with students), which could be reflected through tone, emotion and body language. Twenty-five percent $(25 \%)$ of the students highlighted teachers' tendency to encourage and motivate students by contextualizing concepts in real-life situations, as evidence of Enthusiasm. Finally, $15 \%$ of the respondents mentioned energetic responsiveness as one of their criteria to decide the degrees of Enthusiasm in teachers.

Effective use of passion and voice were the most preferred factors ranked by students in an investigation into the effect of performance techniques on student enthusiasm, attention, and learning and engagement (Hains-Wesson, 2011). The ability to change the tone of voice was similarly pointed out as a characteristic of an engaging tutor 
(Delaney et al., 2009). They found that instructors who were engaging also demonstrated passion and enthusiasm in their teaching, and in the process they inspired their learners. Passion and enthusiasm signaled that teachers cared about their students. Passion can be defined as the sum effect of the use of performance techniques, such as vocalization, spatial awareness, and eye contact (Hains-Wesson, 2011).

\section{Learning and Thinking}

Answering the question, "How does an instructor contribute to your learning and thinking?", the participants revealed that the key sub-components of this indicator were the use of questions, the use of techniques, and familiarity with learners' individual characteristics. The key term "questions" was announced by $37 \%$ of respondents. They mostly highlighted instructors' use of higher order questions (e.g., asking challenging questions, questions that foster students' critical thinking and thought-provoking questions). Another evidence of learning and thinking was the application of appropriate techniques that could broaden students' views and engage them in activities such as discussions, quizzes and problem-solving cases (33\% of the respondents).

Different activities highlighted by the students to improve their Learning-Thinking points to the fact that teachers need to be flexible enough to adapt their teaching methods to the different preferred learning and thinking styles in the classroom. These responses were in line with the findings of Delaney et al. (2009), who observed effective teachers were thought to be flexible, practical and reflective. Such teachers were able to alter their teaching strategies and to situate course material in real-life contexts. This indicator was mentioned previously as a sign of pedagogical content knowledge. This is interesting, as on the level of student evaluation of teaching this suggests a teacher could be judged on the same item in two different categories. The third feature of Learning-Thinking $(30 \%)$ was familiarity with learners' individual specifications; a teacher's consideration of individual psychological and linguistic characteristics can help him/her present the materials in a way suitable for the level of students' experience and understanding.

\section{Delivery}

The last question inquired about the aspects of Delivery: "How does an instructor deliver lessons competently?" In response, the students identified two main indicators: performance techniques $(58 \%)$ and using teaching aids $(42 \%)$. The most frequently mentioned sample of teaching aids were audio-visual devices (30\% of the respondents), suggesting that the participants expected effective teachers to implement some form of technology, even if as simple as PowerPoint slides. This expectation is not surprising, as PowerPoint slides could create a professional impression (Jones, 2003), and generally technology occupies a huge proportion of the everyday life of this generation of students. These findings were consistent with those of previous studies in which students perceived effective teachers as those who would optimally use resources and were well-prepared with clear materials and aims (Delaney et al., 2009; Patrick \& Smart, 1998). As Lee (2010) state:

The delivery metaphor, common among educators, suggests that teaching is viewed as transfer of information. Effective delivery suggests transfer of an 
object from one place to another. In the classroom, the object is content/ subject matter and students' minds are the destination, while the teacher is the conduit (p. 107).

As for the performance activities, $58 \%$ of the respondents suggested that teachers should plan to improve their students' practical utility through lecturing, discussion and group work activities.

\section{Discussion}

To examine what learners understood by the term "effective teaching", this study investigated their understanding of the five commonly evaluated categories of teaching: Knowledge, Preparation-Organization, Learning-Thinking, Delivery and Enthusiasm. A critical review of the findings of this study illustrated that the students' views of the key characteristics of good teaching were in line with recent pedagogical shifts in education which insist on teacher-student interaction as dialogic rather than monologic style of communication. In such educational systems, students' criticality is improved through thought-provoking questions, learners are active participants in the learning process through various performance activities, teachers and learners are highly motivated, teachers are responsive to learners' individual needs, and learning is integrated with technology.

The findings of the study have both pedagogical and theoretical implications. The findings support techniques, theories and models dealing with teacher effectiveness, as they underscored the significance of this particular variable in academic settings. Furthermore, the observations can bring about practical implications to be considered and implemented by teachers, syllabi designers, authors of academic books, curriculum planners and all those involved in education. From the perspective of methodology, the findings revealed that the two instruments developed could be successfully used in Iranian (and similar) settings to collect data about teachers and help achieve an objective method of student-centered teacher evaluation.

Given the results reported in this research, a series of other research projects could be undertaken. Some of the interesting topics to be explored are as follows: (a) to investigate effective teaching in other studies, researchers can incorporate other variables recognized to be significant in the literature; (b) in this study, gender differences were considered but not included as an effective factor in the statistical analysis; similarly, the age of the participants was not considered as a variable. Other researchers may want to inspect the impact of such variables, especially through a larger sample size; and (c) other existing and methodologically relevant instruments could be put to test in future studies.

Considering the fact that research is an ongoing process configured by the information and facilities at the disposal of researchers, the present study faced two limitations: (a) due to time limitations, only 80 participants were included in this research; and (b) all the students were from Azad university branches, Iran. The selection of this range of students was again a constraint imposed on the research process. 


\section{Conclusion}

It is evident that human knowledge obtained and deepened in the socio-cultural sphere is of crucial significance to sustainable development. In order to gain mutual understanding and respect towards the adressee, it is fundamentally essential to use the properly developed means of communication in negotiations. This is so because people develop through interpersonal contacts and exchange of information and experience. Misunderstanding is far more dangerous for discourse than the lack of understanding. Therefore, to foster the speaker and make him/her function at a variety of socio-cultural levels on both macro and micro scale, we have to teach him/her how to communicate and be creative in expressing his/her thoughts. To achieve this goal, we are in dire need of effective second language education. Effective second language education, consequently, is an important part of education for sustainable development.

One can use either deductive or inductive approach, depending on the learner's needs, experience and age. The objective should be the working knowledge of the second language demonstrated by the learner's functional competence as well as socio-cultural competence allowing for making use of different language functions, depending on the situation

This study probed into the notion of effective L 2 teaching as perceived by a sample of higher-education students. For some reasons, student evaluation of teacher performance has been considered to be a source without reliable outcomes. A serious obstacle is that students' observations are thought to lack objectivity. Contrary to these assumptions, there are scholars who emphasize the centrality of students in the teaching/learning process, as well as the importance of their evaluation of the teaching effectiveness they observe. Advocating this student-centered approach, this study scrutinized student evaluations as a measure of teaching effectiveness, to determine what is responsible for good teaching from the perspective of higher-education students at L2 departments in Iran. As a result of a substantial investigation of the literature, five major indicators of teaching effectiveness (viz. Preparation-Organization, Knowledge, Learning-Thinking, Enthusiasm and Delivery), with their sub-components, shaped the analytic frame of the study. The data were collected through a specifically designed questionnaire via electronic connections. The results, broadly speaking, emphasized major characteristics such as fluency and confidence in presenting lessons, clarity of presentation, having rapport with students, asking challenging questions, and effective performance techniques. This study could inspire further research into various dimensions of teaching effectiveness, especially if other indicators and different samples are chosen to be investigated.

\section{References}

Adams, C., \& Pierce, R. (1999). Characteristics of effective teaching. Language Teaching, 102-107.

Balam, E. M., \& Shannon, D. M. (2010). Student ratings of college teaching: A comparison of faculty and their students. Assessment \& Evaluation in Higher Education, 35, 209-221.

Barnes, B. D., \& Lock, G. (2010). The attributes of effective lecturers of English as a foreign language as perceived by students in a Korean university. Australian Journal of Teacher Education, 35(1), 139-152. 
Bell, T. (2005). Behaviors and attitudes of effective foreign language teachers: Results of a questionnaire study. Foreign Language Annals, 38(2), 59-70.

Behroozi, B., \& Karimnia, A. (2017). Educational context and ELT teachers' corrective feedback preference: Public and private school teachers in focus. International Journal of Research in English Education, 2(2), 10-15.

Borg, S. (2006). Teacher cognition in language teaching: a review of research on what language teachers think, know, believe, and do. Language Teaching, 36(2), 81109.

Brosh, H. (1996). Perceived characteristics of the effective language teacher. Foreign Language Annals, 29(2), 125-136.

Calabria, F. M. (1960). Characteristics of effective teachers. Educational Research Bulletin, 92-100.

Chen, J. (2012). Favourable and unfavourable characteristics of EFL teachers perceived by university students in Thailand. International Journal of English Linguistics, 2(1), 213-219.

Çoklar, A. N., \& Kabakçi. Yurdakul, I. (2017). Technology Integration Experiences of Teachers. Discourse and Communication for Sustainable Education, 8(1), 19-31.

Delaney, J., Johnson, A., Johnson, T., \& Treslan, D. (2009). Students' perceptions of effective teaching in higher education. Paper presented at the Edge Conference, Canada.

Delaney, J., Johnson, A. N., Johnson, T. D., \& Treslan, D. L. (2010). Students’ perceptions of effective teaching in higher education. Memorial University of Newfoundland, Distance Education and Learning Technologies.

Dunkin, M. J., \& Biddle, B. J. (1974). The study of teaching. Holt, Rinehart \& Winston. Fang, Z. (1996). A review of research on teacher beliefs and practices. Educational Research, 38(1), 47-65.

Feldman, K. A. (1978). Course characteristics and college students' ratings of their teachers: What we know and what we don't. Research in Higher Education, 9(3), 199-242.

Feldman, K. A. (1988). Effective college teaching from the students' and faculty's view: Matched or mismatched priorities. Research in Higher Education, 28(4), 291344.

Gursoy, D., \& Umbreit, W. T. (2005). Exploring students' evaluations of teaching effectiveness: What factors are important? Journal of Hospitality \& Tourism Research, 29, 91-109.

Hains-Wesson, R. (2011). The impact of performance skills on students' attitudes towards the learning experience in higher education. Issues in Educational Research, 21, $22-41$.

Horwitz, K. (1988). The beliefs about language learning of beginning university foreign language students. The Modern Language Journal, 72(3), 283-294.

Hollins, E. R. (2011). Teacher preparation for quality teaching. Journal of Teacher Education, 62, 395-407.

Iliško, Dz. (2007). Teachers as Agents of Societal Change. Journal of Teacher Education for Sustainability, 7, 14-26.

Johnston, B., \& Janus, L. (2003, April). Teacher professional development for the less commonly taught languages [Research Report]. The Center for Advanced Research on Language Acquisition. Minneapolis: University of Minnesota. 
Johnson, K. E. (1992). The instructional decisions of pre-service English as a second language teachers: New directions for teacher preparation programs. In J. Flowerdew, M. Brock and S. Hsia, (eds.). Perspectives on second language teacher education. Hong Kong. City Polytechnic of Hong Kong. 115-134.

Kagathala, A. B. (2002). A study of the effectiveness of teachers of secondary school in Gujarat. Journal of Education and Psychology, 59(1), 26-33.

Kalantari, E., \& Karimnia, A. (2012). The application of a translation model to foreign Language teaching methodology. World Applied Sciences Journal, 16 (10), 14161426.

Karimnia. A., \& Kay, E. (2015). An Evaluation of the Undergraduate TEFL Program in Iran: A Multi-Case Study. International Journal of Instruction, 8(2), 83-98.

Karimnia, A., \& Mohammadjafari, F. (2017). Critical ESP textbook evaluation: The case of visual arts textbook. Sustainable Multilingualism, doi: http://dx.doi.org/ 10.1515/sm-2017-0020.

Kissau, S. P., Algozzine, B., \& Yon, M. (2012). Similar but different: The beliefs of foreign language teachers. Foreign Language Annals, 45(4), 580-598.

Lee, J. (2010). Personal and social-contextual factors in K-12 academic performance: An integrative perspective on student learning. Educational Psychologist, 45(3), 185-202.

MacGregor, J. (2003). Students' perceptions of quality in higher education. Quality Assurance in Education, 11(1), 15-20.

Mansour, N. (2009). Science teachers' beliefs and practices: Issues, implications and research agenda. International Journal of Environmental \& Science Education, $4(1), 25-48$.

Miedema, S. (2017). Pedagogy is coming back! Some hopeful signs for sustainable general education and worldview education. Discourse and Communication for Sustainable Education, 8(1), 121-128, doi: 10.1515/dcse-2017-0009.

Park, G. P., \& Lee, H. W. (2006). The characteristics of effective English teachers as perceived by high school teachers and students in Korea. Asia Pacific Education Review, 7(2), 236-248.

Patrick, J., \& Smart, R. M. (1998). An empirical evaluation of teacher effectiveness: The emergence of three critical factors. Assessment \& Evaluation in Higher Education, 23(2), 165-178.

Pipere, A. (2016). Envisioning complexity: Towards a new conceptualization of educational research for sustainability. Discourse and Communication for Sustainable Education, 7(2), 68-91. doi: 10.1515/dcse-2016-0017.

Salite, I. (2015). Searching for sustainability in teacher education and educational research: Experiences from the Baltic and Black Sea Circle Consortium for educational research. Discourse and Communication for Sustainable Education, 6, 21-29.

Shavelson, R. J., \& Stern, P. (1981). Research on teachers' pedagogical thoughts, judgments, decisions, and behavior. Review of Educational Research, 51, 455-498.

Shulman, L. S. (1986). Those who understand: Knowledge growth in teaching. Educational Researcher, 15, 4-14.

Skye, J. (2015). Why is sustainable development important? Retrieved from http://greenliving.lovetoknow.com 
Strong, M., Gargani, J., \& Hacifazlioglu, O. (2011). Do we know a successful teacher when we see one? Experiments in the identification of effective teachers. Journal of Teacher Education, 62, 367-382.

Thompson, N., \& Thompson, S. (2008). The critically reflective practitioner. Hampshire: Palgrave Macmillan.

Vadillio, R. S. M. (1999). Research on the good language teacher. EPOS, 15, 347-361.

Wachtel, H. K. (1998). Student evaluation of college teaching effectiveness: A brief review. Assessment \& Evaluation in Higher Education, 23, 191-212.

Wang, J., Lin, E., Spalding, E., Klecka, C. L., \& Odell, S. J. (2011). Quality teaching and teacher education: A kaleidoscope of notions. Journal of Teacher Education, $62,331-338$.

Yair, G. (2008). Can we administer the scholarship of teaching? Lessons from outstanding professors in higher education. Higher Education, 55, 447-459.

Correspondence concerning this paper should be addressed to Amin Karimnia, Department of English Language Teaching, Fasa Branch, Islamic Azad University, Iran. Email:aminkarimnia@yahoo.com

Appendix

Name: Male $\square$ Female Age:

Please answer the following questions carefully. Answering these questions accurately requires honest reflection on how you really think, feel and act. If you do not have enough space below each question, copy the number of the question on the back of the page and write the answer there.

1. Does your teacher use warm-up exercises?

2. Is your teacher fluent and confident in presenting new lesson?

3. Does your teacher help you set goals for your learning and keep track of your progress?

4. Does your teacher want you to explain your thinking?

5. Does you teacher make you work hard so you learn what you need to know?

6. Does your teacher use teaching aids?

7. Is your teacher able to answer unexpected questions?

8. Is your teacher presentation clear to you?

9. Can your teacher establish rapport with you and other students?

10. Does your teacher encourage you to do your best?

11. Is your teacher energetic?

12. Do you get choices in how to complete activities?

13. What types of questions does your teacher ask?

14. What kind of techniques does your teacher use?

15. Does your teacher pay attention to students' individual characteristics?

16. Does your teacher encourage you to his/her best?

17. Does your teacher make you feel that he/she cares about you?

18. Is your teacher helpful when you ask questions?

19. Does your class stay busy and not waste time?

20. Are classroom rules and ways of doing things are fair? 
21. Does your teacher check to make sure you understand what he/she is teaching?

22. Does your teacher explain another way if you don't understand something?

23. Does your teacher take time to summarize what you learn each day?

24. Does your teacher help you when you need it or don't understand something?

25. Does your teacher know when you work hard and are doing your best?

26. Do you learn to correct your mistake?

27. Does your teacher want you to improve your thinking skills?

28. Is your teacher responsive to your questions and needs?

29. Do you learn a lot almost every day?

30. Does your teacher tell you what you are learning and why?

31. Does your teacher make university work interesting? 